International Business Management 13 (6): 228-233, 2019

ISSN: $1993-5250$

(C) Medwell Journals, 2019

\title{
Evaluation of the Extent the Services of School Access Programme (SAP) is Needed in South-East Nigeria
}

\author{
${ }^{1}$ Kingsley O. Okoro, ${ }^{2}$ Edith Edikpa and ${ }^{2}$ Bartholomew C. Nwefuru \\ ${ }^{1}$ Department of Science Education \\ ${ }^{2}$ Department of Educational Foundations, University of Nigeria, Nsukka, Enugu State, Nigeria
}

\begin{abstract}
The focus of this study was to evaluate the extent to which the services of the school access programme is needed in South-East Nigeria. The population of the study was 14,141 respondents and the sample size was 389. A 6-item structured questionnaire was the instrument used for the collection of the data of the study. Mean, standard deviation and t-test were used for data analysis. It was found that both teachers and students in South-East Nigeria needed the services of school access programme at a Very Great Extent (VGE). The implementers of the programme should ensure that both teachers and students obtain optimal impact from the programme. The programme should be implemented effectively and evaluation should be conducted on the programme periodically to determine the successful outcome, impact and shortfalls.
\end{abstract}

Key words: Programmes, services, school access programme, Nigeria, determine the successful, shortfalls

\section{INTRODUCTION}

Programmes are established to provide quality services to their clients. Such services are potentially needed by the programme beneficiaries and it could be educational, medical, training, social and technical services. Medical services are provided to patients through the platform of health posts, health centres and hospitals. Educational services are provided to programme recipients through primary, secondary, colleges of education, polytechnics and university outfit. Training service may be in the form of workshops, seminars and skill acquisition oriented in nature. Social services include the provision of electricity, pipe born water, constructions of roads, bridges, civic centres and community town halls. Technical services include engineering, electrical and mechanical services provided to the community by programme stakeholders. Essentially, the aim of establishing programmes is to provide quality services to the people. Therefore, the focus of government or concerned citizens is to establish a programme to provide quality services to the people. However, it is not only to provide services but the programmes are also established to eradicate problems confronting different communities. Some communities are faced with the problem of electricity, roads, water and health provisions at inadequate levels. It is the responsibility of government and private sector to establish programmes that will accelerate the reductions of problems facing the various communities within the country. This means that the social and educational problems facing each community are potentially addressed by establishing programmes that can effectively offer solutions to those problems.
Furtherm ore, the Federal Government of Nigeria has been on the forefront towards the revitalization of the educational system. One of the major focuses of the country is the introduction of ICT into the educational system. Okwor (2012) defined ICT as the use of computer and telecommunications system in the collation, collection, analysis, processing, manipulation, storage, retrieval, transmission and communication of data in different forms which may include audio, visual and audiovisual formats. Essentially, ICT is regarded as the packaging of many technologies such as computer, telecommunications and media, it has become the major driving force for global socio-economic, political and educational development. The labour force globally is highly sensitive to ICT utilization (Yusuf, 2005). On this premise, the universal service provision fund under the National communication Commission of Nigeria introduced the School Access Programme (SAP) into the educational system in 2007 (Anonymous, 2007). The school access programme is an ICT outfit designed by universal service provision fund to stimulate ICT and software applications in Nigeria secondary schools (Anonymous, 2007). The programme also facilitates the internet services of the school. The staff and students can open and operate email have access to Facebook communication and other internet explorations. Jegede and Owolabi (2003) explained that the introduction of school access programme into the educational system of the nation will boost the internet exploration of the schools. It is not only internet service that the programme facilitates, the school access programme is also very useful to the research activities of the school. The recipients of the programme can have access to enough and rich educational materials that can 
facilitate teaching and learning of different subjects in the school. Consequently, recipients of the programme can lay hand on well-packaged materials that can accelerate teaching and learning in Nigerian schools. In order to ensure the programme's effective delivery of its services, the programme sponsors are expected to carry out a fundamental evaluation. Such activity will keep the programme viable at a sustainable level. Such a process of evaluation that is fundamental is termed programme "needs assessment". The first step in the process of programme evaluation is needs assessment and it is the process whereby needs are identified and priority among them established. There are many needs within a particular community and limited resources necessitate satisfying only those needs which are prioritized as highly important (Bailey and Deen, 2002). In conducting a needs assessment, the evaluator examines the population that the programme intends to target to determine whether the need/problem as conceptualized in the programme actually exists in the population. Furthermore, needs assessment examines the people affected by the problem and the measurable effects that are caused by the problem. It is not necessary to undertake an intervention without properly assessing the needs for that programme embarking on such programme will result in a great deal of waste of funds, if the need did not exist or was misconceived. A programme that did not do needs assessment before embarking on its service may have the illusion that they have eradicated the problems/needs when in fact there was no need in the first place.

The needs assessment also involves research and regular consultation with community stakeholders and the beneficiaries of the programme before the development and implementation of the programme. Hence, it should be a bottom-up approach. This means that problems can be identified early as the process would have involved the community in identifying the need and hereby allowed them the opportunity to identify the potential barriers. Involvement of the community stakeholders at the early stage of the programme reduces the potential of push-back miscommunications and incomplete information later on.

Furthermore, the needs assessment involves the location of where the problem exists. For instance, government may want to construct a borehole and such a programme has to be mounted at a location where it will serve larger members of the community and also where such borehole does not exist before. Siting the borehole where another borehole exists is a waste of fund in the first place. Therefore, the location of where the problem/need exists is very crucial in the needs assessment. Needs assessment also involves identifying methods that could be used to find a solution to the existing problem. This means that the evaluator should conduct a task analysis to determine the best way to perform tasks involved in a programme. Such analysis requires that the job description standard should be set out clearly.

Also, needs assessment also involves the performance of gap analysis and this requires that an evaluator compare current to the desired or necessary situation. The difference or the gap between the two situations will help identify the need, purpose and aim of the programme. Needs assessment requires the identification of priorities and importance. This is necessary because several problems/needs exist but such problems/needs are examined because of their significance to programme goals and the desires of the recipient of the programme. An assessment of priority and importance should be done considering the cost-effectiveness of the programme and the number of people that desires that programme. The intensity or level of desire for a programme by the community should be determined and articulated and expressly stated in the evaluator's report. The measurable effects of the problem on the community should be determined and conveyed to the programme sponsors by an evaluator. The effective way of proffering solution to an existing problem should be minutely stated and possible methods that will enhance growth and development should be adequately reported to the programme stakeholders. The school access programme in South-East Nigeria, however, needs evaluation to show whether the programme is needed by teachers and students in South-East Nigeria. On this prem ise needs assessment should be conducted on the school access programme in South-East Nigeria to determine the intensity or level of desire for the programme by both teachers and students the measurable effects of the absence of the programme on teachers and students in Southeast Nigeria and whether the school access programme is of great need to both teachers and students for ICT acquisition and research activities. However, there was no empirical evidence in the literature to show the extent the services of the school access programme are needed by both teachers and students in South-East Nigeria. Such critical empirical evidence that is lacking compelled the researchers to investigate this study.

Statement of the problem: School access programme is established by universal service provision fund to deliver its services to both teachers and students in Nigeria. Funds are wasted when services that are not needed are being offered to the clients of a programme. It could be that the fund earmarked for school access programme to deliver its service to its clients is a waste. There was no empirical evidence to show that students and teachers in South-East Nigeria need school access programme or its services. Therefore, the problem of the study is: to what extent do teachers and students in South-East Nigeria need the services of school access programme? 
Int. Business Manage., 13 (6): 228-233, 2019

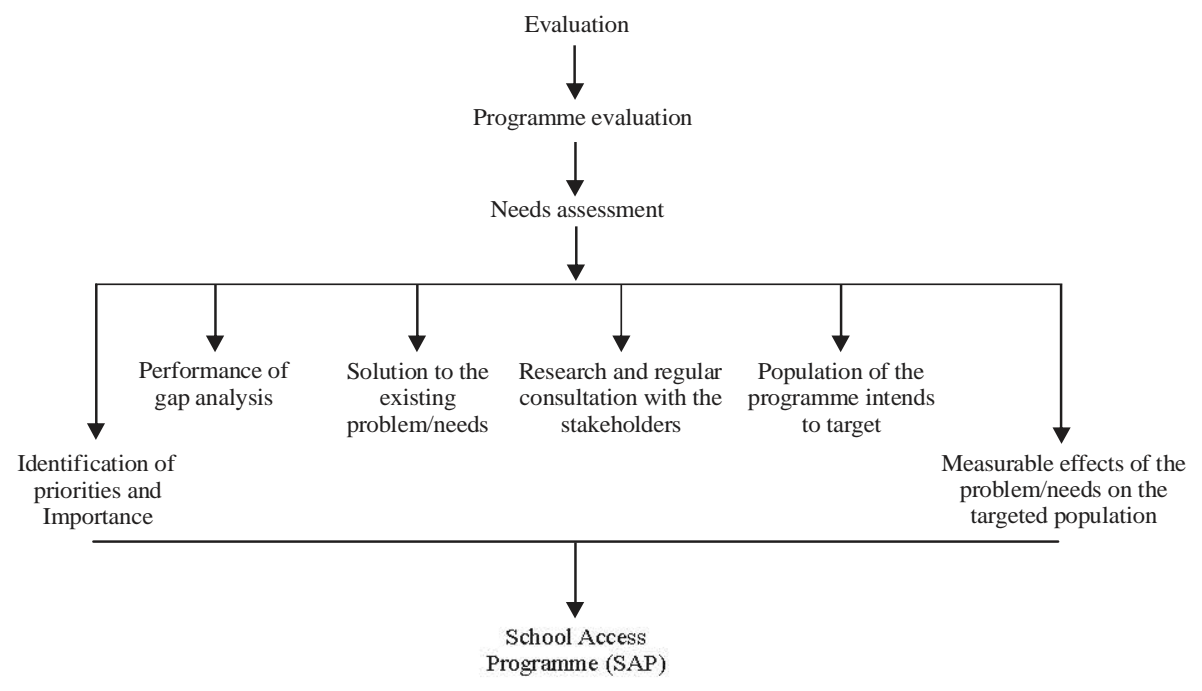

Fig. 1: Conceptual framework of the study

The purpose of the study: The purpose of the study was to conduct a needs assessment on school access programme in South-East Nigeria. Specifically, the study evaluated the extent teachers and students in South-East Nigeria need the services of school access programme in South-East Nigeria.

Significance of the study: Practically, the findings of this study will be of immense educational value to the government, Ministry of Education, programme planners, developers of programmes, programme implementers, the school heads and the society at large. Specifically, the government of Nigeria would by the findings of this study become aware of the extent the service of a school access programme is needed in South-East, Nigeria. Such awareness would enable government either to continue funding the programme or discontinue the waste of her fund. The findings of the study will enable the Ministry of Education to be aware of teachers and students that received the services of the school access programme. This will enable the ministry to be aware of the quality of services the school access programme rendered to its recipients. The findings of the study will be a working tool for programme planners. They will have it as a criterion that all the programme they intend to plan must go through needs assessment evaluation. The findings of the study will also enable programme developers to be aware that the needs assessment should be included in the design of the programmes they intend to develop. This will enable them to avoid funding a programme that is not in existence. The findings of the study will enable programme implementers to be aware of whether school access programme implementation should continue or not. The implementers will continue the implementation of the programme, if the services or the programme is needed by its recipients. The school heads will by the findings of the study become aware of the extent the services of the programme are needed not only in schools but in the whole of South East of Nigeria. This will enable the school heads to put up effective implementation of the programme. The findings of the study will enable the society to be aware of what happened to the programme. This will enable the society to know the area it can help.

The scope of the study: The content scope of the study includes the evaluation of the extent the services of the school access programme is need by teachers and students in South-East Nigeria. The geographical scope of the study was South-East Nigeria.

Conceptual framework: Figure 1 shows the conceptual relationship of evaluation, programme evaluation and needs assessment with school access programme. The needs assessment aims to identify priorities and importance of the programme among other target goals as identified above.

Research questions: To what extent are the services of school access programme needed by teachers and students in South-East Nigeria?

Hypothesis: There is no significant difference between the mean ratings of teachers and students on the extent to which the services of SAP are needed by teachers and students in South-East Nigeria.

\section{MATERIALS AND METHODS}

Design: The study employed an evaluation research design. The evaluation design is a structure or strategy 
designed by an evaluator to determine the overall effectiveness of a programme by comparing the objectives proposed in the programme as against the achieved objectives using an appropriate model of programme evaluation (Campbell and Stanley, 2004). The design is considered appropriate and suitable because it addressed critically the research question of the study. The design enabled the researcher to collect appropriate and reliable data, interpreted the data succinctly and above all provided feedback to programme stakeholders which include policy makers, implementers, programme sponsors, donors, administrators, staff and clients.

Area of study: The study was carried out in South-East Nigeria which consists of five states namely: Abia, Anambra, Ebonyi, Enugu and Imo State. These five states also termed South-East Nigeria is tied together by a common language and unique cultural background. The zone is made up of trades, civil servants and educationists. 38 secondary schools benefit from the school access programme in Abia and Enugu States, respectively. In Imo State, 37 secondary schools benefited from the programme while Ebonyi and Anambra had 35 each making total number of 183 secondary schools that benefited from the school access programme in South-East Nigeria (Anonymous, 2007). The zone was chosen for the study because of the uniqueness of her culture and from her budgetary allocation. Education is a major industry in the South-East zone.

The population of the study: The population of the study consists of 14,141 comprising 1945 male teachers, 2196 female teachers, 3866 SSII male students and 6134 SSII female students of 2017/2018 session that offered computer education studies in South-East Nigeria.

Sample and sampling technique: The sample size of this study was 389 respondents. Stratified proportionate, random sampling, simple random sampling and cluster random sampling techniques were used in the study, stratified random sampling techniques were used to draw 54 and 60 from both male and female teachers, respectively, 106 and 169 from both male and female students, respectively. Stratified proportionate random sampling technique was used to ensure that an adequate proportion of both teachers and student relative to their compositions in the total population were included in the sample. A slip of paper or lucky dip method of simple random sampling technique was used to draw 389 respondents. Simple random sampling technique was used to draw the respondents because it gave each respondent an equal and independent chance of being included in the sample. Cluster random sampling technique was used to draw two states ( $30 \%$ of the five states) and 55 secondary schools ( $30 \%$ of 183 secondary schools) that benefited from the school access programme in South-East), respectively. Cluster random sampling technique was used to ensure the bridge of time frame and to avoid excess waste of fund.

Instrument for data collection: A questionnaire titled School Access Programme Questionnaire (SAPQ) was used to collect the pertinent and relevant data of the study. SAPQ consist of section A and B. Section A was designed to solicit information on the personal characteristics of the respondents while section $B$ which is a 6 item instrument was designed to measure the extent the services of a school access programme is needed by teachers and students in South-East Nigeria. The instrument was rated on a four-point liker scale of Very Great Extant (VGE), Great Extant (GE), Low Extant (LE) and Very Low Extent (VLE).

Validation of the instrument: The SAPQ was given to three experts in both departments of science education and vocational teacher education both from the University of Nigeria Nsukka for face validation.

Method of data collection: The method of data collection of the study was carried out by the researchers with the help of five trained research assistants. The questionnaire was administered to 389 respondents and they were made to fill them within 1 week after which the researchers or assistants retrieved the instrument from the respondents.

Reliability of the instrument: The School Access Programme Questionnaire (SAPQ) was administered to 10 SSII students and 10 teachers of Government College Ikom LGA in Cross River State of Nigeria. The scores generated from the respondents were used to estimate the internal consistency of the instrument using the Cronbach alpha reliability coefficient method. The estimated reliability coefficient was 0.892 .

Method of data analysis: Descriptive statistics (mean and standard deviation) was used to answer the research question and student $t$-test was used to test the hypothesis at 0.05 level of significance.

\section{RESULTS AND DISCUSSION}

Research question: To what extent are the services of School Access Programme (SAP) needed by teachers and students in South-East Nigeria. Result in Table 1 revealed that items $1-6$ had their mean values ranged from 3.53-3.69 which is within the real limit of 3.50-4.00 indicating that the extent to which the items are needed by its beneficiaries is to a very high extent. The cluster mean of 3.59 and 3.60 for teachers and students implies that the extent to which the services of SAP are needed by its 
Int. Business Manage., 13 (6): 228-233, 2019

Table 1: Mean and standard deviation of teachers and students on the extent SAP is needed by teachers and students in South-East Nigeria

\begin{tabular}{|c|c|c|c|c|}
\hline \multirow[b]{2}{*}{ Items statement } & \multicolumn{2}{|c|}{ Teachers $=114$} & \multicolumn{2}{|c|}{ Students $=275$} \\
\hline & $\operatorname{Mean}(\overline{\mathrm{X}})$ & $\mathrm{SD}$ & $\operatorname{Mean}(\overline{\mathrm{X}})$ & $\mathrm{SD}$ \\
\hline SAP provides the ICT needs of the students & 3.54 & 0.84 & 3.62 & 0.81 \\
\hline SAP provides the ICT needs of the teachers & 3.69 & 0.87 & 3.58 & 0.87 \\
\hline SAP enhances ICT application in teaching and learning of various subjects & 3.58 & 0.83 & 3.59 & 0.80 \\
\hline SAP provides resources materials for teaching and learning & 3.61 & 0.83 & 3.58 & 0.89 \\
\hline SAP provides internet services of the school & 3.57 & 0.87 & 3.65 & 0.85 \\
\hline SAP enhances browsings needs of teachers & 3.53 & 0.81 & 3.55 & 0.88 \\
\hline Cluster mean & 3.59 & 0.84 & 3.60 & 0.85 \\
\hline
\end{tabular}

Table 2: t-test analysis of the significant difference between the mean ratings of teachers and students on the extent to which the services of SAP are needed by teachers and students

\begin{tabular}{lcccccccc}
\hline Status & $\mathrm{N}$ & Mean & SD & df & t-values & Level of sig. & Sig. (2-tailed) & Decision \\
\hline Teachers & 114 & 3.59 & 0.35 & 387 & -1.167 & 0.05 & 0.697 & Accept \\
Students & 275 & 3.60 & 0.43 & - & - & - & - & - \\
\hline
\end{tabular}

beneficiaries in South-East Nigeria is to a very high extent. The standard deviation of the 6 items ranged from $0.81-0.89$ indicating that the respondents were homogenous in their responses.

Hypothesis: There is no significant difference between the mean rating of teachers and students on the extent to which the services of a school access programme is needed by teachers and students in South-East Nigeria.

Result in Table 2 shows the t-test for independent samples assuming equal variance. The results from the test shows $\mathrm{t}(387)=0.697, \mathrm{p}>0.05$. Thus, the null hypothesis of no significant difference is accepted, since, the p-value $(0.697)$ is $>0.05$ level of significance. The researchers, therefore, concludes that there was no significant difference in the mean ratings of teachers and students on the extent to which the services of SAP are needed by its beneficiaries in South East zone of Nigeria.

The findings of the study showed that the extent to which the services of SAP are needed by teachers and students in South-East Nigeria is at a very great extent. The standard deviation on the extent to which beneficiaries of SAP need the services of SAP cluster around the mean indicating uniformly that the recipients of SAP require the services of the programme. The findings by UNICEF (2009) which centred on Child-Friendly Schools (CFS) showed that the programme is highly needed by its recipients. The study supports the present study which its findings indicate that the services of SAP are needed in South-East Nigeria. The government should continue to fund school access programme in Nigeria. The programme should be expanded to accommodate more secondary schools in South-East Nigeria. The school access programme can boast the income generation of the schools. Income will be realized through the school access programme in the area of typing and printing of materials by the communities, opening and checking of emails, receiving and sending of emails, browsing and even Facebook communication. All these will accelerate the income generation of the school and the fund could be used to maintain the upkeep of the programme (Anonymous, 2007). Apart from exploring the usefulness of SAP to the research activity of the school, the school access programme facilitates the application of ICT in the teaching and learning of various subjects in the school. Thus, the introduction of school access programme to the educational system of the country, teachers can now brilliantly apply ICT in the teaching and learning of their various subjects. This can improve students understanding and performance in those subjects. The school access programme has prospects that can empower Nigerian youths. Aniebonam explained that the school access programme has the potentials of solving some problems experienced by Nigerian youths such as unemployment, illiteracy and poverty. The youths can achieve this by engaging themselves in the skill acquisition training exercise for future self-reliance. The school access programme also facilities the acquisition of skills by Nigerian students. The skill emphasized by the school access programme is ICT skill-oriented training that embraced up creativity among the youths. The school access programme has the potential of not only introducing new teaching and learning practices but also for acting as a catalyst to revolutionalize the education system (Yusuf, 2005).

\section{CONCLUSION}

Because teachers and students need the services of the school access programme in South-East Nigeria at a very great extent, the implementers of the programme should ensure that both teachers and students obtain optimal impact from the programme. The programme should be implemented effectively and evaluation should be conducted on the programme periodically to determine the successful outcome, impact and shortfalls. Such 
periodic evaluation will provide empirical feedback to the stakeholders of the programme which they can use for decision making.

\section{REFERENCES}

Anonymous, 2007. Universal service provision fund strategic plan 2007-2011. National Communication Commission, Abuja, Nigeria.

Bailey, S.J. and M.Y. Deen, 2002. A framework for introducing program evaluation to extension faculty and staff. J. Extension, Vol. 40,
Campbell, L. and O. Stanley, 2004. Process of programme evaluation. J. Hum. Educ., 3: 20-25.

Jegede, P.O. and J.A. Owolabi, 2003. Computer education in Nigerian secondary schools: Gaps between policy and practice. Meridian A. Middle Sch. Technol. J., 6: 1-11.

Okwor, S., 2012. Integrating of ICT into Education System. Tashiwa Networks Limited, Enugu, Nigeria,

UNICEF., 2009. Child-Friendly Schools Manual. United Nations Children's Fund, New York, USA., ISBN:978-92-806-4376-3, Pages: 244.

Yusuf, M.O., 2005. An investigation into teachers self-efficacy in implementing computer education in Nigerian secondary schools. Meridian, Vol. 8, 